Discussion Paper No. 741

\title{
FOREIGN DIRECT INVESTMENT AND THE WELFARE EFFECTS OF COST HARMONIZATION
}

\author{
Anthony Creane \\ and \\ Kaz Miyagiwa
}

May 2009

The Institute of Social and Economic Research Osaka University

6-1 Mihogaoka, Ibaraki, Osaka 567-0047, Japan 


\title{
Foreign direct investment
}

\section{and the welfare effects of cost harmonization ${ }^{\dagger}$}

\author{
Anthony Creane ${ }^{a}$ and Kaz Miyagiwa ${ }^{\text {b,c }}$
}

Foreign direct investment (FDI) gives foreign firms access to local labor and inputs, thereby harmonizing costs between foreign and domestic firms relative to exports. This paper investigates the welfare effects of such cost harmonization in strategic environments, finding that when the number of home firms is sufficiently close to the number of foreign firms, FDI reduces home welfare, whether FDI raises or decreases foreign firms' marginal costs. An implication is that under the same conditions, a country is harmed by tax harmonization on products that bring foreign taxes on product it imports inline with domestic ones for products.

${ }^{a}$ Department of Economics, Michigan State University, East Lansing, MI 48824-1038 USA; creane@msu.edu

${ }^{\mathrm{b}}$ Department of Economics, Emory University, Atlanta GA 30322-2240 USA; kmiyagiwa@gmail.com

' ISER, Osaka University, 6-1 Mihogaoka, Ibaraki, Osaka 567-0047, Japan

${ }^{\dagger}$ We thank to C. Davidson, S. Matusz and J. Tirole, as well as participants at Michigan State seminar for their thoughtful comments on a preliminary version of this paper. All errors are our own.

JEL: F12, F21

Key words: Foreign investment, Cournot competition, welfare 


\section{Introduction}

Countries often have contradictory attitudes regarding foreign direct investment. Xenophobia and a concern of foreign ownership of domestic assets induce countries to discourage FDI. In some cases domestic competitors also prefer to keep the foreign rivals away from low-wage domestic labor. In other cases, domestic firms welcome FDI to 'level the playing field' so that foreign rivals face similar production costs. For the latter case, the case of the U.S. auto market and Japanese manufacturers comes to mind. Originally, the Japanese auto manufacturers exported all of their cars to the United States, taking advantage of lower labor costs in Japan. But this began to change in the early 1980's when they faced export restrictions. To avoid trade barriers present and potential and also to take advantage of tax breaks from state governments seeking to expand employment, Japanese auto makers began to set up plants within the United States, even though relocation raised marginal costs for them. ${ }^{1}$ Thus, in general FDI harmonizes costs between domestic and foreign firms but as a result average industry cost may be higher or lower relative to exporting. The objective of this paper is to examine the effects on domestic country welfare from these marginal cost changes associated with FDI.

While the strategic effects of FDI have been extensively studied in the literature, surprisingly there has been little analysis of the welfare implications of these cost changes, perhaps because the answer seems obvious. On one hand, when FDI lowers marginal costs for foreign firms, domestic competitors are clearly harmed while consumers benefit. If FDI instead increases marginal costs for foreign firms, then the effects reverse. This tradeoff between consumer and to domestic firm welfare seems straightforward at first. If the harm to domestic

\footnotetext{
${ }^{1}$ A firm may also choose marginal cost increasing FDI if its fixed costs of operation decrease sufficiently. The decrease in fixed cost could come from avoiding fixed-cost non-tariff barriers.
} 
firms from cost reducing FDI outweighs the benefit to consumers, then FDI deteriorates domestic country welfare. Then by the logical extension it would seem that cost-raising FDI in the same circumstance must improve domestic country welfare. However, welfare can decrease from FDI, regardless of whether FDI raises or lowers the foreign firms' cost.

To develop the reason intuitively, consider the Cournot duopoly with one foreign firm and one domestic firm competing in the domestic market. As noted above, FDI produces opposing effects on domestic consumer and producer welfare, but in this case the gain to one side is always less in magnitude than the loss to the other. To see why, note that, whether foreign costs are greater or less than domestic costs, FDI brings foreign costs closer in line to domestic costs. Since demand slopes downward, domestic consumer surplus is convex and decreasing in marginal costs. Thus, the gain to domestic consumers when a foreign firm's costs decrease to domestic costs (and so domestic price decreases) is less than the loss to consumer welfare when a foreign firm's costs increase to domestic costs. For an analogous reason the loss to domestic producer surplus from when foreign costs decrease is greater than the gain when foreign costs increase. Thus, FDI reduces welfare in a Cournot duopoly regardless of whether it is cost increasing or cost decreasing.

This result extends to the multi-firm model: if there are nearly as many foreign firms as domestic firms in industry, FDI always reduce domestic welfare, whether FDI reduces or increases marginal costs for foreign firms. Furthermore, when FDI involves large changes in costs, then if the proportion of domestic firm ownership is at least 30 percent, FDI reduces welfare, whether it is cost-raising or cost-reducing. In the case of cost-raising FDI, FDI can reduce welfare regardless of the proportion of domestic ownership, if the initial cost difference is substantial. 
Our work is related to the work of Salant and Shaffer (1999) and Lahiri and Ono (1988), both of which examine the welfare effect of changes in Cournot firms' marginal costs in the absence of foreign competition. Salant and Shaffer (1999) show that introducing a cost asymmetry in a Cournot oligopoly, while holding industry output constant, improves welfare. It is well know that, in a Cournot oligopoly with constant marginal costs, industry output and price are independent of distribution of individual firm marginal costs when average marginal cost are held constant (see Bergstrom and Varian 1985). Thus, a mean-preserving spread in marginal costs has no effect on price and hence consumer surplus, but reduces average cost of production as lower cost firms produce more while higher cost firms contract. Hence welfare improves.

Since here FDI reduces the cost asymmetry among firms when half or more of the firms are domestic, our result - that FDI decreases welfare - may appear to be equivalent to the SalantShaffer (1999) result. However, there are crucial differences. First, recall that the Salant-Shaffer (1999) result depends on the constancy of industry output, while here FDI also affects industry output (as average marginal costs are not held constant). Further, while in Salant and Shaffer (1999) aggregate profits are (naturally) used for welfare calculus, the welfare measure here excludes foreign profits. Hence the efficiency loss or gain by the foreign firms does not enter into the welfare calculation.

Because of these differences in assumptions, our results are driven by additional effects than those responsible for the Salant-Shaffer (1999) result. To illustrate this point, consider the limiting case of our model, in which the proportion of firms that are domestic approaches one. Then, the model approaches the Salant-Shaffer model, so one might expect that our results would converge with Salant and Shaffer (1999); i.e., the diminishing cost asymmetry would reduce domestic welfare. However, we find that cost increasing FDI always raises domestic welfare. 
Second, as noted above, when the number of domestic firms is sufficiently close to that of foreign firms, FDI decreases domestic welfare, no matter what the cost difference is between domestic and foreign producers. Thus, even if FDI results in a significant decrease in industry average cost, the cost harmonization still decreases domestic welfare. In contrast, in Salant and Shaffer (1999) welfare improves because a mean-preserving spread reduces industry average cost. Finally, as we obtain conditions when FDI reduces welfare when a majority of producers are foreign, we find cases when welfare decreases even though FDI both increases the spread of the marginal costs (which is a benefit in Salant and Shaffer 1999) and decreases industry average cost (which increases domestic output).

In related work, Lahiri and Ono (1988) show for an asymmetric Cournot oligopoly that a small cost reduction by an inefficient firm can lower welfare. ${ }^{2}$ This has the following intuitive explanation. A cost reduction by any firm decreases price and raises consumer surplus. However, a marginal reduction in the marginal cost of an inefficient firm expands its output, replacing output by lower-cost firms and as a result raises industry average cost. If the latter dominates the beneficial effect on consumer surplus, then welfare falls.

By symmetry the Lahiri-Ono (1988) model implies that a small cost increase by an inefficient firm is welfare improving if a small cost reduction is welfare decreasing. The critical difference is that in our model, when a cost reduction lowers welfare, a cost increase can also reduce welfare in the same setting. The source of this difference results from different questions being asked. To begin, Lahiri and Ono's (1988) welfare measure includes all firms as well as consumer surplus, while we exclude foreign profits. More importantly, Lahiri and Ono's (1988) result requires that the cost-reducing firm be small relative to the market, while our result does

\footnotetext{
${ }^{2}$ See also Farrell and Shapiro (1990).
} 
not require that the cost reduction to be small, and can hold when the firms are large relative to the market or multiple firms receive the cost reduction. Indeed, Lahiri and Ono (1988) find that if the cost-reducing firm has more than a third of the market then the cost reduction increases welfare. In contrast, we find that the foreign firms can have roughly half the market and its cost reduction will reduce welfare. Further, we find that even if marginal costs rise for foreign firms, domestic welfare can decrease.

Our findings have implications on other work that examines foreign direct investment. For example, consider recent work on examining the role uncertainty has on FDI under strategic competition; e.g., Sung and Lapan (2000) for exchange rates uncertainty and Qiu and Zhou (2006) for demand uncertainty with learning. Our findings suggest that when the exchange rate uncertainty affects costs, then the welfare effects for the domestic country are not solely driven by uncertainty since FDI also has a cost harmonization effect. Likewise, the results under demand uncertainty may not carry over to the case of cost uncertainty due to the cost harmonization effect of FDI.

The implication of this result holds in other environments as well, including tax harmonization. Consider the same model but with firms facing identical costs of production and their location fixed. Assume the foreign government imposes a tax $t_{f}(t<0$, a subsidy) on firms producing in their country while the domestic government imposes a tax $t_{\mathrm{d}}$. If the foreign government harmonizes its tax to the domestic government's tax, then domestic welfare decreases under the same conditions we derive for FDI to be welfare reducing.

In the next section we introduce the basic modeling assumptions. In section three, we present the equilibrium outcomes and in the subsequent section the welfare analysis of a single foreign firm choosing FDI instead of exporting. Section five extends the analysis to multiple 
(including all) foreign firms choosing FDI. The penultimate section extends the model by considering partial harmonization, that is, if the foreign cost only changes in the direction of the domestic costs. This section also examines the effect of product differentiation, and how the model can be interpreted in terms of tax harmonization. The final section concludes.

\section{Model environment}

There are $n(\geq 2)$ firms competing in the domestic market. As we are considering plant location, it is natural to assume Cournot competition. To focus on the strategic implications from cost harmonization effects from FDI, assume the firms are producing identical goods and ignore other costs, e.g., fixed or setup costs.

Production costs for firm $i$ are linear and depend only on the country of production: $c_{i}(\mathrm{q})$ $=c_{N} q_{i}$, where $q_{i}$ denotes firm $i$ 's output, and the subscript $\mathrm{N} \in(d, f)-d$ omestic, foreign indicates country- or nation-specific cost. Domestic firms always have marginal costs $c_{\mathrm{d}}$. Foreign firms face marginal costs $c_{\mathrm{f}}$ when they export (which includes any transport costs) but $c_{\mathrm{d}}$ if they locate in the domestic country. This assumption is made to simplify the presentation with no qualitative effects and in section 6 we show this by relaxing this assumption and allowing for the foreign costs to become a convex combination of $c_{d}$ and $c_{f}$ when they choose FDI. We assume an interior solution: the values of $c_{d}$ and $c_{f}$ are such that all firms produce in equilibrium.

We now introduce two key parameters of our analysis. A first is the fraction of firms that are domestic. We denote this by the letter $d$, so there are $d \cdot n$ domestic firms and $(1-d) \cdot \mathrm{n}$ foreign firms. Note that $d$ ranges from zero to $(n-1) / n$. When $d=0$, all firms are foreign, while $d=(n-$ $1) / n$ all firms but one are domestic. The other key parameter we use is the number of foreign firms that engage in FDI. We denote this number by $x \in[0,(1-d) \cdot n]$. 
Turning to the market demand, we consider a representative consumer model with quadratic preferences given by $\mathrm{U}(\mathrm{Q})=Q-Q^{2} / 2$, where $Q$ is aggregate output. From this aggregate inverse demand is given by $\mathrm{P}=1-Q$, with $Q=\sum_{j=1}^{n} q_{j}$.

\section{Equilibrium}

In this section we solve for the Cournot-Nash equilibrium. As each firm simultaneously sets output, firm $i$ chooses $q_{i}$ to maximize profit

$$
\left(1-\sum_{j=1}^{n} q_{j}-c_{i}\right) q_{i}
$$

Firm $i$ 's output choice depends on its $\operatorname{costs}\left(c_{d}\right.$ or $\left.c_{f}\right)$, which in turn depends on its location of production - foreign or domestic. From the first order conditions of all the firms, a firm producing domestically has equilibrium output

$$
q_{d}(x)=\left[1-((1-d) \cdot n+1) c_{d}+(1-d) \cdot n \cdot c_{f}+x \cdot\left(c_{d}-c_{f}\right)\right] /(n+1)
$$

A foreign firm that chooses to export has equilibrium output

$$
q_{f}(x)=\left[1-(d \cdot n+1) c_{f}+(d \cdot n) \cdot c_{d}+x \cdot\left(c_{d}-c_{f}\right)\right] /(n+1) .
$$

There are $d \cdot n+x$ firms producing in the domestic country and $(1-d) \cdot \mathrm{n}-x$ firms producing in the foreign country. Aggregate output is, from equations (2) and (3),

$$
Q(x)=\left[n\left(1-d \cdot c_{d}-(1-d) c_{f}\right)-x \cdot\left(c_{d}-c_{f}\right)\right] /(n+1)
$$


From equations (1) - (3) we can derive the representative firm's profit whose production occurs domestically:

$$
\pi_{d}(x)=\left[1-(n(1-d)+1) c_{d}+n(1-d) c_{f}+x\left(c_{d}-c_{f}\right)\right]^{2} /(n+1)^{2}=\left(q_{d}\right)^{2}
$$

This expression is clearly decreasing in $\mathrm{x}$ only when FDI is cost-reducing $\left(c_{d}<c_{f}\right)$. Thus, costreducing (cost-raising) FDI harms (benefits) the domestic firms. Aggregate domestic profits are $d \cdot n \cdot \pi_{d}$

Given the preferences on our representative consumer, consumer surplus is

$$
C S(x)=Q(x)^{2} / 2=\left[n\left(1-d \cdot c_{d}-(1-d) c_{f}\right)-x \cdot\left(c_{d}-c_{f}\right)\right]^{2} / 2(n+1)^{2} .
$$

It is immediate from the above that cost-reducing (cost-raising) FDI increases (decreases) domestic consumer surplus. Domestic country welfare $\mathrm{W}(\mathrm{x})$ is defined as the sum of total profits to domestic firms and consumer surplus. Given the definitions above, we have

$$
W(x)=n \cdot d \cdot \pi_{\mathrm{d}}(x)+Q(x)^{2} / 2 .
$$

\section{Welfare effects of FDI by a single foreign firm}

We suppose that $x=0$ initially, i.e., the status quo has all foreign firms export from their home countries, and analyze the welfare effect of a single foreign firm switching to FDI $(x=1)$. For the case of cost-reducing FDI, the status quo may be the result of a deliberate ban on FDI, or prohibitively high fixed setup costs (e.g., through bureaucratic requirements). ${ }^{3}$ Then, relaxing

\footnotetext{
${ }^{3}$ We abstract from the specific nature of costs imposed to deter FDI (which do not enter into domestic welfare) so as to focus on the question at hand: what occurs if some or all foreign firms are allowed to engage in FDI.
} 
such restrictions could immediately induce all the foreign firms to relocate in the domestic country (thereby gaining a cost reduction). However, it is possible to control the number of firms engaging in FDI by eliminating the fixed costs for, or giving permits to, only a subset of foreign firms. ${ }^{4}$ Even in the case of cost-raising FDI, foreign firms may choose FDI over exporting if the (un-modeled) fixed costs of operation are sufficiently lower domestically. ${ }^{5}$ In other cases, inducing FDI might require subsidizing setup costs of FDI or alternatively raise the actual or potential future cost of export as in the case of Japanese automakers as noted in the introduction. However, here we abstract from these points to ask whether generally FDI is welfare worsening.

Using (4), the general expression for the welfare change from a single foreign firm choosing FDI (i.e., $\mathrm{x}=0$ to $\mathrm{x}=1$ ) is:

$$
W(1)-W(0)=\left(c_{f}-c_{d}\right) \frac{\left(c_{d}-c_{f}\right)\left(4 d n^{2}(1-d)-1\right)+\left(1-c_{f}\right) 2 n(1-2 d)}{2(1+n)^{2}} .6
$$

\footnotetext{
${ }^{4}$ Alternatively, if the fixed costs imposed by the domestic country affects the foreign firms differently (that is, the foreign firms are heterogeneous with respect to these costs), then a reduction in these cost would result in only some of the foreign firms choosing FDI. For example, the foreign firm's ability to negotiate a bureaucratic barrier impose could vary greatly.

${ }^{5}$ Host country governments often setup enterprise zones to induce foreign firms, where they offer tax holidays, and subsidize construction of infrastructure. As such inducements would further worsen the domestic welfare effects (and bias our results towards FDI being welfare worsening) we abstract from this effect.

${ }^{6}$ Differences must be used because the integer effect can influence results. The classic case in which this occurs is in the excess entry result (Mankiw and Whinston 1986). Recently, Sen (2005) has shown that previous results regarding the licensing of a cost reduction are sensitive to whether differences or derivatives are examined. We will note below where this affects the results here as well.
} 
To gain insight to the expression on the right-hand side, we begin by considering three canonical environments.

Case 1: $d=1 / 2$ (the number of foreign firms is exactly half of the total producers, which includes the standard case of one domestic and one foreign firm). Then, equation (5) becomes:

$$
W(1)-\left.W(0)\right|_{d=\frac{1}{2}}=\frac{-\left(c_{d}-c_{f}\right)^{2}(n-1)}{2(n+1)}<0 .
$$

The right-hand side of (6) is independent of the sign of $\left(c_{d}-c_{f}\right)$. Thus, regardless of whether FDI lowers or raises the foreign firm's marginal cost of production, a switch from exporting to FDI by a single foreign firm reduces domestic welfare when the firms are evenly distributed between foreign and domestic ownership.

The basic intuition to this result was outlined in the introduction but additional detail may help clarify the result. The key thing to note is that $c_{d}$ is the focal point. To see why this drives the result, it is easiest to consider each part of domestic welfare (consumer and producer surplus) separately. To begin, consider consumer welfare. When $c_{d}<c_{f}$ consumers benefit and when $c_{d}$ $>c_{f}$, they are harmed. But since consumer surplus is convex and decreasing in the marginal cost of a foreign firm, their gain from an $\varepsilon$ cost decrease to $c_{d}$ is less than their loss from an $\varepsilon$ cost increase to $c_{d}$ (see $C S(x)$ and also figure 1$)$.

Turning to producer surplus, a domestic firm's profit is also convex, but increasing in the marginal cost of a foreign firm (see $\pi_{d}(x)$ ). Thus, their loss from an $\varepsilon$ cost decrease to $c_{d}$ is greater than their gain from the foreign firm having an $\varepsilon$ cost increase to $c_{d}$. As a result, when the relative magnitudes of the change and consumer and producer surplus roughly balance, domestic welfare decreases. This occurs, e.g., when the producers are evenly distributed between foreign 
and domestic ownership. Using continuity we conclude:

Proposition 1: When sufficiently close to half of all producers are domestic, then a foreign firm switching to FDI always reduces domestic welfare regardless of whether domestic marginal costs are lower or higher than foreign ones.

The case when half the firms are domestic producer includes the standard model in international trade of a duopoly with one firm located in each country. For this special case the result is surprising especially in the context of Salant and Shaffer (1999). There, a mean-preserving spread in marginal costs reduces average industry cost, and hence improves welfare. Here, the foreign marginal cost can be much higher than the domestic cost so that FDI can reduce average marginal cost significantly (especially in the two firm case) and yet welfare decreases.

Case 2: $\mathbf{d}=\mathbf{0}$ (all firms are foreign). Equation (4) then becomes

$$
W(1)-\left.W(0)\right|_{d=0}=\frac{\left(c_{f}-c_{d}\right)\left[\left(c_{f}-c_{d}\right)+2 n\left(1-c_{f}\right)\right]}{2(1+n)^{2}} .
$$

In this case, since there is no domestic profit, what matters is a change in consumer surplus. Then, it is easy to see that domestic welfare increases if FDI is cost-reducing $\left(c_{d}<c_{f}\right)$ but decreases if FDI is cost-increasing $\left(c_{d}>c_{f}\right){ }^{7}$

Case 3: $\boldsymbol{d}=(\boldsymbol{n}-\mathbf{1}) / \boldsymbol{n}$, (only one foreign firm). This modifies equation (5) to:

\footnotetext{
${ }^{7}$ To see that if $c_{d}>c_{f}$, welfare decreases, note that if the expression were ever positive, it would be positive at $n=2$. However, at $n=2$ the expression is negative.
} 


$$
W(1)-\left.W(0)\right|_{d=\frac{n-1}{n}}=\left(c_{f}-c_{d}\right) \frac{\left.-3(n-1)\left(c_{f}-c_{d}\right)-(n-2)\left(2-c_{f}-c_{d}\right)\right]}{2(1+n)^{2}}
$$

Here, the effects are subtler than in the first two cases. Specifically, whether cost-reducing or cost-increasing, FDI can reduce domestic welfare. Consider first cost-reducing FDI $\left(c_{f}>c_{d}\right)$. As can easily be verified from (7), cost-reducing FDI always decreases welfare despite the benefit it confers on consumers. The reason is that an output expansion by the lone foreign firm (whose cost was higher with exporting) induces all domestic firms to contract output but domestic firms are more efficient than the foreign firm. Thus, this result is akin to the result obtained by Lahiri and Ono (1988) that an expansion by an inefficient firm can reduce welfare. The difference is that here the foreign firm can have a higher share of the market than in Lahiri and Ono (1988); and the cost reduction for the inefficient firm can be large.

Since cost-reducing FDI reduces welfare when there is only one foreign firm one might be tempted to conclude that cost-raising FDI must increase domestic welfare in this case. Surprisingly, however, this symmetry in results does not always hold. To see this, note that the numerator on the right-hand side of equation (7) is increasing in $c_{d}$. At $d=(n-1) / n$,

$$
c_{d}=\left(1+c_{f}\right) / 2
$$

is the maximum $c_{d}$ such that there is an interior solution (i.e., all firms produce). At this value of $c_{d}$, the numerator on the right-hand side of (7) becomes $3\left(1-c_{f}\right) / 2>0$ and, since FDI is costincreasing $\left(c_{d}>c_{f}\right)$, welfare decreases. ${ }^{8}$ Essentially, if the efficiency loss from FDI by the single foreign firm is sufficiently large, then domestic welfare can decrease despite the market being

\footnotetext{
${ }^{8}$ If one used the derivative of $W$ with respect to $x$, the conditions for FDI to harm domestic welfare are stronger.
} 
almost completely dominated by domestic producers.

The symmetries in results of course can occur. For example, let $n>2$ and $c_{f}$ be sufficiently close to $c_{d}$. Then, as can easily be checked from Equation (7), cost-increasing FDI increases welfare. This case, however, is also somewhat surprising in the context of Salant and Shaffer (1999). Here, as $d$ approaches unity so that, in the limit there are no foreign firms, the present model approaches the one considered in Salant and Shaffer (1999). Yet, Salant and Shaffer (1999) have found that cost harmonization always decreases welfare, while here cost harmonizing FDI can increase welfare. ${ }^{9}$

Summarizing our findings up to this point we have

Proposition 2: (A) When none of the firms are domestic $(d=0)$, FDI reduces welfare if costincreasing and improves welfare if cost-reducing. That is, welfare changes are determined by changes in consumer surplus.

(B) When nearly half of the firms are domestic $(d=1 / 2)$, FDI reduces welfare, whether costreducing or cost-raising.

(C) When there is only one foreign firm $(d=(n-1) / n)$, cost-reducing FDI always lowers welfare, while cost-increasing FDI may or may not decrease welfare.

The proposition implies that the welfare effect of FDI is sensitive to the direction of cost harmonization and on the distribution of firm ownership between domestic and foreign. In the

\footnotetext{
${ }^{9}$ Indeed, if one examined the derivative of $W$ with respect to $x$, and take the limit as $x \rightarrow 0$ and $d \rightarrow 1$, the conclusion would be that domestic welfare always benefits from FDI when $c_{d}>c_{f}:\left.\frac{d W}{d x}\right|_{x \rightarrow 0, d \rightarrow 1}=\frac{n\left(c_{d}-c_{f}\right)\left(1-c_{d}\right)}{(1+n)^{2}}$
} 
remainder of this section we search general conditions on the distribution of ownership under which FDI reduces welfare, regardless of the direction of cost change induced by FDI. We thus return to the general case. Note first that the right-hand side of (5), $W(1)-W(0)$, is quadratic in $d$. Further, the coefficient of $d^{2}$ is positive so the parabola opens upward. Furthermore, it is straightforward to show that there is at most a single $d \in[0,(n-1) / n]$ such that (5) equals zero. While this is proved in the appendix, we present this formally as a lemma.

\section{Lemma: There are at most one $d$ on $[0,(n-1) / n]$ that such that $W(1)-W(0)=0$ :}

$$
\begin{array}{r}
d^{*}=\frac{n\left(c_{d}-c_{f}\right)-\left(1-c_{f}\right)+\left[\left(n^{2}-1\right)\left(c_{d}-c_{f}\right)^{2}+\left(1-c_{f}\right)^{2}\right]^{\frac{1}{2}}}{2 n\left(c_{d}-c_{f}\right)} \\
=\frac{1}{2}+\frac{-\left(1-c_{f}\right)+\left[\left(n^{2}-1\right)\left(c_{d}-c_{f}\right)^{2}+\left(1-c_{f}\right)^{2}\right]^{\frac{1}{2}}}{2 n\left(c_{d}-c_{f}\right)}
\end{array}
$$

We will proceed by deriving the conditions for cost-reducing and cost-increasing FDI to reduce welfare separately and then combining the results for general conditions. Beginning with cost-increasing FDI, we know that $W(1)-W(0)<0$ at $d=0$ from Proposition 2.A. However, from Proposition 2.C, $W(1)-W(0)$ can be positive or negative at $d=(n-1) / n$. Suppose $W(1)-$ $W(0)>0$ at $d=(n-1) / n$. Then since $W(1)-W(0)$ is quadratic, $W(1)-W(0)=0$ has a unique $d$ $\left(d^{*}\right)$; see Figure 2. Then, Figure 2 indicates that FDI increases welfare if $d>d^{*}$. Suppose instead that $W(1)-W(0)<0$ at $d=(n-1) / n$. Then $W(1)-W(0)<0$ at any $d \in[0,(n-1) / n]$, and hence there is no $d$ that satisfies the equation $W(1)-W(0)=0$ (see Figure 3 ). Thus, in this case costincreasing FDI reduces welfare for any $d \in[0,(n-1) / n]$.

To summarize, cost-increasing FDI always reduces domestic welfare for all $d \in[0,(n-$ 1)/n] if $W(1)-W(0)<0$ at $d=(n-1) / n$. We saw already in case 3 that this inequality holds if $c_{d}$ 
is sufficiently higher than $c_{f}$. Finally, since we have assumed an interior solution (i.e., all firms produce when $x=0$ ), we need to ensure that all domestic firms produce at such high $c_{d}$ when $d<$ $(n-1) / n$. Proving this (see the appendix) yields the next result.

\section{Proposition 3: If $c_{d}$ is sufficiently high relative to $c_{f}$, cost-increasing FDI by a single foreign} firm always reduces domestic welfare no matter what the distribution of firm ownership is.

Turning next to cost-reducing FDI, we have then that $W(1)-W(0)>0$ at $d=0$ (Proposition 2.A) and $W(1)-W(0)<0$ at $d=(n-1) / n$ (Proposition 2.C) Thus, by the intermediate-value theorem there is a unique $d \in[0,(n-1) / n]$, denoted by $d^{*}$, at which $W(1)-$ $W(0)=0$ (See Figure 4). We also know from Proposition 2.B that $d^{*}<1 / 2$. Thus, if the fraction of domestic producers is $d^{*}$ or greater, cost-reducing FDI is welfare decreasing.

We proceed to characterize the $d^{*}$ such that cost-reducing FDI decreases domestic welfare regardless of the distribution of firm ownership. From (5) we see that as $c_{f} \rightarrow c_{d}$, the negative effect from FDI disappears but this is because the effect of FDI goes to zero in the limit. So we consider instead what occurs as the difference between $c_{d}$ and $c_{f}$ increases. To do so, hold $c_{d}$ constant and increase $c_{f}$. Then, calculus reveals that $d^{*}$ decreases. Since we know that FDI reduces welfare for $d>d^{*}$, the range of $d$ at which FDI reduces welfare widens; see Figure 2. To get a sense of the limit, we compute the largest $c_{f}$, given $c_{d}$, that guarantees an interior solution (that is, all firms produce in equilibrium): this is given by $c_{f}=\left(1+(n-1) c_{d}\right) / n{ }^{10}$ Substituting this value into the expression for $d^{*}$ in the lemma we obtain the lowest $d^{*}$ such that, when cost

\footnotetext{
${ }^{10}$ Unlike when $c_{d}>c_{f}$, in this case as more foreign firms engage in FDI there are more low cost firms so that the strongest condition on $c_{f}$ must be imposed to guarantee an interior solution.
} 
differences are maximal, cost-reducing FDI reduces domestic. This limiting value of $d^{*}$ is given by $\left(2 n-1-[2 n(n-1)]^{1 / 2}\right) / 2 n$. This term is increasing in $n$ so taking the limit, as $n \rightarrow \infty \mathrm{d}^{*} \rightarrow 1$ $-2^{-1 / 2} \approx .29$. It follows that if at least 30 percent of firms are domestic, cost-reducing FDI reduces welfare.

Now that we have the conditions under which FDI reduces welfare when it is costincreasing and it is cost-reducing, we combine those conditions to arrive at the general conclusion for welfare-decreasing FDI.

Proposition 4: When at least $30 \%$ of the firms are domestic producers and marginal cost differentials are sufficiently large, then FDI by a single foreign firm reduces domestic welfare, regardless of whether FDI is cost-increasing or cost-decreasing.

Proposition 4 gives a sufficient condition, but not a necessary one for welfare-decreasing FDI. That is, the percentage of domestic firms can easily be less than $30 \%$, and yet FDI can reduce domestic welfare. For example, assume that currently there are 50 firms in the market $(n$ $=50)$ and only 5 are domestic producers $(d=10 \%)$. Assume further that domestic marginal cost $c_{d}=.5$ and foreign marginal costs $c_{f}=.55$ so that FDI is cost reducing $(v$. cost-increasing FDI Proposition 3). In this case, having a foreign firm switch to FDI reduces welfare. Note that here as the foreign firm switching to FDI reduces the average of the marginal costs but increases the dispersion, and still domestic welfare decreases. This contrasts sharply with Salant and Shaffer (1999), who find that increased dispersion holding the average marginal cost constant always increases welfare. 


\section{Welfare effect of FDI by multiple foreign firms}

In the preceding section we examined the welfare effect of FDI by a single firm. In this section we extend the analysis to the welfare effect of FDI by more than one foreign firm. Even if FDI by one foreign firm reduces domestic welfare, the intuition for this result, given in the introduction, may suggest that the benefits to either consumers or to domestic producers could dominate the harms to the other side when a sufficient number of foreign firms switch from exporting to FDI. To evaluate this supposition consider a welfare change at any arbitrary $x \geq 1$.

$$
\begin{aligned}
& W(x)-W(x-1)= \\
& \quad\left(c_{f}-c_{d}\right) \frac{\left(c_{d}-c_{f}\right)\left(4 d n^{2}(1-d)-1\right)+\left(1-c_{f}\right) 2 n(1-2 d)+2 x\left(c_{f}-c_{d}\right)(1+2 d n)}{2(1+n)^{2}}
\end{aligned}
$$

The right-hand side of (9) is linear in $x$ with the positive coefficient, $\left(c_{d}-c_{f}\right)^{2}(1+2 d n) /(1+n)^{2}$. However, $W(x)-W(x-1)$ can be negative for all $x$ if the remainder of the RHS of (9) is sufficiently negative. Then, since $\sum_{x=1}^{(1-d) n} W(x)-W(x-1)<0$; the country is better off with no FDI. Clearly, even if $W(x)-W(x-1)>0$ for some $x$, the sum $\sum_{x=1}^{(1-d) n} W(x)-W(x-1)$ could still be negative so that the country is still better off with no FDI. However, $\sum_{x=1}^{(1-d) n} W(x)-W(x-1)$ can be positive, in which case having all firms choose FDI $(x=(1-d) n)$ maximizes domestic welfare. Finally, if $W(1)-W(0)>0$, then obviously $x=(1-d) n$ maximizes domestic welfare. This leads to the next proposition.

\section{Proposition 5: Domestic welfare is maximized when either all foreign firms switch to FDI}


or no foreign firms do.

The question then is whether having all foreign firms switch to FDI can change the initial harm to the domestic country. To see this, compute the domestic welfare when all foreign firms choose to export:

$$
W(0)=\left\{n \cdot d \cdot\left[1-(n(1-d)+1) c_{d}+n(1-d) c_{f}\right]^{2}+n^{2}\left(1-d \cdot c_{d}-(1-d) c_{f}\right)^{2}\right\} /(n+1)^{2}
$$

and domestic welfare when they all choose FDI

$$
W((1-d) n)=\left[n \cdot\left(1-c_{d}\right)^{2}(n+2 d)\right] / 2(n+1)^{2} .
$$

Taking the difference yields the change in domestic welfare form all the foreign firms switching to FDI

$$
\begin{aligned}
& W((1-d) n)-W(0) \\
& \quad=-\frac{n^{2}}{(n+1)^{2}}(1-d)\left(c_{d}-c_{f}\right)\left[(1-d)\left(c_{d}-c_{f}\right)(1+2 d n)+1(1-2 d)\left(1-c_{d}\right)\right]
\end{aligned}
$$

Suppose that $d=1 / 2$ as in proposition 1 , that is, when half of the producers are domestic producers. Then, the second bracketed term disappears and so (10) becomes

$$
\left.W((1-d) n)\right|_{\mathrm{d}=1 / 2}-W(0)=-n^{2}\left(c_{f}-c_{d}\right)^{2} / 8(n+1)<0 .
$$

Then, by continuity, we conclude that, if the number of domestic producers is sufficiently close to one half, then foreign direct investment by all the foreign firms always lowers welfare regardless of whether FDI raises or lowers foreign firms' marginal costs. Thus, proposition 1 holds when all foreign firms engage in FDI. 
Proposition 6: Suppose that sufficiently close to half of all producers are domestic. Then

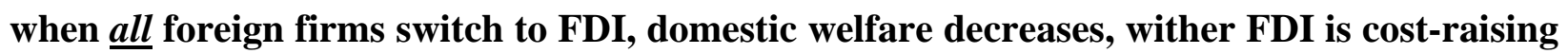
or cost-reducing.

In Proposition 3 we showed that $W(1)-W(0)<0$ regardless of $\mathrm{d}$ if FDI is sufficiently cost-increasing. This conclusion, despite the fact that $W(x+1)-W(x)$ is increasing in $x$, also survives when all foreign firms switch to FDI. The proof follows similar steps as those leading to proposition 3. First, the right-hand side of (10) is quadratic in $d$ and its parabola opens upward. Thus, there is an analogous result to the lemma: if it exists, there is a unique $d$, denoted $d^{* *}$, such that $W((1-d) n)-W(0)=0 .{ }^{11}$ Second, when $d=0$, the result is the same: costincreasing (cost-reducing) FDI lowers (increases) domestic welfare. Further from proposition 6 we know that at $d=1 / 2$, FDI lowers welfare. We then substitute the greatest $c_{d}$ such that the interior condition holds into (10). Solving for $d$ we obtain a modified form of $d^{*}$, which we denote $d^{\prime \prime}=(2 n+1) / 2 n$. Since $d^{\prime \prime}>(n-1) / n, W((1-d) n)-W(0)<0$ for all $d \in[0,(n-1) / n]$. Thus proposition 3 can be extended as

\section{Proposition 7: With cost-increasing FDI, when domestic marginal cost are sufficiently greater than foreign marginal cost, then $\underline{\text { all }}$ foreign firms switching to FDI always reduces domestic welfare no matter how large the domestic share of production.}

The case of cost-reducing FDI $\left(c_{f}>c_{d}\right)$ also remains qualitatively unaffected when all firms choose FDI. As before, FDI increases welfare at $d=0$. We also know that FDI decreases

\footnotetext{
${ }^{11}$ The proof to this modified case nearly follows the proof to the lemma.
} 
welfare at $d=1 / 2$ (proposition 6). Then by continuity there exists $d^{* *}<1 / 2$ satisfying $W((1-d) n)$ $-W(0)=0$. We now look for the lower bound on $d^{* *}$ when there is a large cost differential. As before we first compute the largest $c_{f}$ that guarantees an interior solution for a given $c_{d}$ (that is, all firms produce in equilibrium): $c_{f}=\left(1+(n-1) c_{d}\right) / n$. Substituting this into $d^{* *}$ we obtain a lower bound of $d$ such that, when cost differences are maximal, FDI reduces domestic welfare. As before, this term is increasing in $n$, and taking the limit we obtain $\left(3-5^{1 / 2}\right) / 2 \approx .39$. We conclude then with

Proposition 8: When at least $40 \%$ of the firms are domestic producers, then all foreign firms switching to FDI always reduces domestic welfare when marginal cost differentials are sufficiently large reqardless of whether domestic marginal costs are lower or higher than foreign ones.

Thus, the condition in proposition 4 is weakened from $30 \%$ to $40 \%$. This modification is unsurprising since $W(x+1)-W(x)$ is increasing in $x$. What perhaps is surprising however is that it is still bounded away from $1 / 2$. Furthermore, for this weakened proposition to have relevance requires that the domestic country's policy will result in all foreign firms choosing FDI. That is, our results offer the following policy implications: the welfare maximizing domestic country should only allow FDI when it is both cost-reducing for foreign firms and the foreign producers are a large majority of all producers. Further, in this case, the government should let all foreign firms to switch to FDI, rather than a few. Otherwise, a restrictive policy towards FDI can be welfare superior. 


\section{Extensions}

In this section we briefly consider how partial harmonization and product differentiation affect the results and how our model can be re-interpreted in terms of tax harmonization with the plant locations fixed.

We begin with the effect of partial harmonization. So far we have assumed that, when a foreign firm chooses FDI, its marginal cost becomes identical to the domestic marginal cost. It is straightforward to generalize the model so that by choosing FDI the foreign firm's marginal cost only partially approaches $c_{\mathrm{d}}$, that is, go from $c_{\mathrm{f}}$ to $\rho \cdot c_{d}+(1-\rho) \cdot c_{f}, \rho \in(0,1]$, where $\rho=1$ is the complete harmonization. We show the implication here only for the case when all foreign firms choose FDI (since this weakened our initial result; cf. propositions 4 and 8 ) and half the firms are domestic producers. Let now $W(\rho, x)$ denote welfare. Following previous steps, it is straightforward to derive that when $d=1 / 2$, then

$$
W(\rho, n \cdot(1-d))-W(\rho, 0)=-n^{2} \cdot x \cdot(2-x)\left(c_{f}-c_{d}\right)^{2} / 8(n+1)<0 .
$$

So, the result of propositions 1 and 6 also holds with partial harmonization. Note that $W(\rho, n \cdot(1-$ d) $)-W(\rho, 0)$ is decreasing in $x$ : the larger the harmonization the greater the harm.

Proposition 9: Suppose that sufficiently close to half of all producers are domestic. Then when all foreign firms switch to FDI, domestic welfare decreases with any partial harmonization, whether FDI is cost-raising or cost-reducing.

Turning next to the effect of product differentiation, its implication can be seen intuitively by considering the duopoly case when the products are perfectly differentiated (that is, the domestic firm is a monopolist for its product and the foreign firm is a monopolist for its 
product). In such a case, the outcome is straightforward as there are only cost effects (that is, no strategic "business stealing” effects). Cost-increasing (cost-reducing) FDI decreases (increases) welfare. Hence, the cost harmonization effect we have found here is stronger the less differentiated the products.

Finally, fix plant locations (i.e., FDI is no longer a choice) so that all foreign firms are locating abroad, and reinterpret our model in terms of tax harmonization. Specifically, assume that $c_{d}=c_{f}=\bar{c}$, but that in each country there is a per-unit tax $t_{d}$ and $t_{f}$, so that domestic marginal costs are $\hat{c}_{d}=\bar{c}+t_{d}$ and $\hat{c}_{f}=\bar{c}+t_{f}$. If tax-harmonization results in the foreign tax being brought closer inline with the domestic tax, then domestic welfare is reduced under the same conditions as before. That is, propositions 1-9 can be re-interpreted in terms of tax harmonization to the domestic tax rate.

\section{Conclusion}

We considered the cost implications of foreign firms relocating their plants into the countries where they sell their products (FDI). In particular, we note that this can have a cost harmonization effect - the costs of all producers are likely to become more closely aligned. If so, then we find a surprising implication: if the number of domestic and foreign firms are roughly equal, then welfare decrease regardless of whether the cost harmonization implies an increase or a decrease in aggregate marginal costs. This result not only highlights the importance of the cost harmonization effect, but has implications in any examination of FDI whenever there are cost differences among producers, for example, the effects of uncertainty and learning on the production location decision (e.g., Qiu and Zhou, 2006). However, as we have demonstrated here, the welfare effects can be dampened or amplified by the cost harmonization effect. 
Therefore, the studies that do not properly account for the cost harmonization effect may over- or understate the true welfare effect.

In terms of home government policy, there is an interesting implication when one relaxes the assumption that the home government is informed as to the firms' costs (see Creane and Miyagiwa 2008). Even if the government does not know whether domestic costs of production are greater or less than foreign costs, it should not encourage (and perhaps should discourage) FDI especially when domestic and foreign firms make up roughly half or more of the industry. 


\section{Appendix}

Lemma: If it exists, there is a unique $d$ that such that $W(1)-W(0)=0$ :

$$
d^{*}=\frac{n\left(c_{d}-c_{f}\right)-\left(1-c_{f}\right)+\left[\left(n^{2}-1\right)\left(c_{d}-c_{f}\right)^{2}+\left(1-c_{f}\right)^{2}\right]^{\frac{1}{2}}}{2 n\left(c_{d}-c_{f}\right)}=\frac{1}{2}+\frac{-\left(1-c_{f}\right)+\left[\left(n^{2}-1\right)\left(c_{d}-c_{f}\right)^{2}+\left(1-c_{f}\right)^{2}\right]^{\frac{1}{2}}}{2 n\left(c_{d}-c_{f}\right)}
$$

Proof: There are only two values of $d$ such that $W(1)-W(0)=0$, thus to prove the lemma only requires showing that the other value can never range over $[0,(n-1) / n]$. The other root is $d^{\prime}=$

$$
\frac{n\left(c_{d}-c_{f}\right)-\left(1-c_{f}\right)-\left[\left(n^{2}-1\right)\left(c_{d}-c_{f}\right)^{2}+\left(1-c_{f}\right)^{2}\right]^{\frac{1}{2}}}{2 n\left(c_{d}-c_{f}\right)}=\frac{1}{2}+\frac{-\left(1-c_{f}\right)-\left[\left(n^{2}-1\right)\left(c_{d}-c_{f}\right)^{2}+\left(1-c_{f}\right)^{2}\right]^{\frac{1}{2}}}{2 n\left(c_{d}-c_{f}\right)} .
$$

Note that numerator is negative and so the second term is negative (positive) when $c_{d}>c_{f}$. To

show that $d^{\prime} \notin[0,1]$, then requires showing that $x\left(c_{f}\right) \equiv \frac{-\left(1-c_{f}\right)-\left[\left(n^{2}-1\right)\left(c_{d}-c_{f}\right)^{2}+\left(1-c_{f}\right)^{2}\right]^{\frac{1}{2}}}{2 n\left(c_{d}-c_{f}\right)}$ is greater than $1 / 2$ when $c_{f}>c_{d}$ and less than $-1 / 2$ when $c_{f}<c_{d}$. In either case, $x^{\prime}\left(c_{f}\right)<0$. Thus, when $c_{f}>c_{d}$ if $x\left(c_{f}\right)>1 / 2$ at the largest possible value of $c_{f}$, then it is always greater than $1 / 2$ when $c_{f}>c_{d}$. To insure an interior solution (positive $q_{f}$ ) a necessary upper-bound on $c_{f}$ is $\left(1+c_{d}\right) / 2$. Substituting $\left(1+c_{d}\right) / 2$ for $c_{f}$ in $x\left(c_{f}\right)$ obtains $(n+1) / n$. When $c_{f}<c_{d}$, if $x\left(c_{f}\right)<-1 / 2$ at the lowest possible value of $c_{f}$ (so that $x\left(c_{f}\right)$ is maximized), then it is always less than $-1 / 2$. Substituting 0 for $c_{f}$ into $x\left(c_{f}\right)$ obtains $\frac{-1-\left[\left(n^{2}-1\right)\left(c_{d}\right)^{2}+1\right]^{\frac{1}{2}}}{2 n c_{d}}=\frac{-1-\left[n^{2}\left(c_{d}\right)^{2}+1-\left(c_{d}\right)^{2}\right]^{\frac{1}{2}}}{2 n c_{d}}<\frac{-\left(1+\left[n^{2}\left(c_{d}\right)^{2}\right]^{\frac{1}{2}}\right)}{2 n c_{d}}<-\frac{1}{2}$.

Proposition 3: If $c_{d}$ is sufficiently high relative to $c_{f}$, cost-increasing FDI by a single foreign firm always reduces domestic welfare no matter what the distribution of firm ownership.

Proof: To complete the proof we need to show that the required $c_{d}$ does not violate our assumption of an interior solution (i.e., all domestic firms must produce). For each $d$, the 
maximum $c_{d}$ such that all firms produce is, $\frac{1+n(1-d) c_{f}}{1+n(1-d)}$, denoted $\bar{c}_{d}$. (Note that if an interior solution holds at $x=0$, then it will hold for any $x>0$ as there are more of the firms are of highcost.) Substituting $\bar{c}_{d}$ into (5) and solving for $d$, denoted $d^{\prime}$, we obtain a variation of (8): $d^{\prime}=$ $\frac{2 n(n+1)-1}{2 n(n+2)}$. Since $d^{\prime}>(n-1) / n$, then for all $d \in[0,(n-1) / n]$, there is a $c_{d}$ such that $W(1)-$ $W(0)<0 . / /$ 


\section{References}

Bergstrom, T.C. and H.R. Varian, 1985, "Two Remarks on Cournot Equilibria," Economics Letters, 19(1), 5-8.

Creane, A. and K. Miyagiwa, 2008, "Information and Disclosure in Strategic Trade Policy," Journal of International Economics, 75(1), 229-244.

Farrell, J. and C. Shapiro, 1990, “Asset Ownership and Market Structure in Oligopoly,” The Rand Journal of Economics, 21(2), 275-292.

Lahiri, S. and Y. Ono, 1988, "Helping Minor Firms Reduces Welfare," The Economic Journal, 98(393), 1199-1202.

Mankiw, G. and M. Whinston, 1986, "Free Entry and Social Inefficiency," The Rand Journal of Economics, 17, 48-58.

Qiu, L.D., and W. Zhou, 2006, "International Mergers: Incentives and Welfare," Journal of International Economics, January, 68, 38-58.

Salant, S. and G. Shaffer, 1999, "Unequal Treatment of Identical Agents in Cournot Equilibrium," American Economic Review, 89(3), 585-604.

Sen, D., 2005, "Fee versus Royalty Reconsidered," Games and Economic Behavior, 53, 141-147.

Sung, H., and H. Lapan, 2000, “Strategic Direct Investment and Exchange-Rate Uncertainty,” International Economic Review 41 (May), 411-423. 

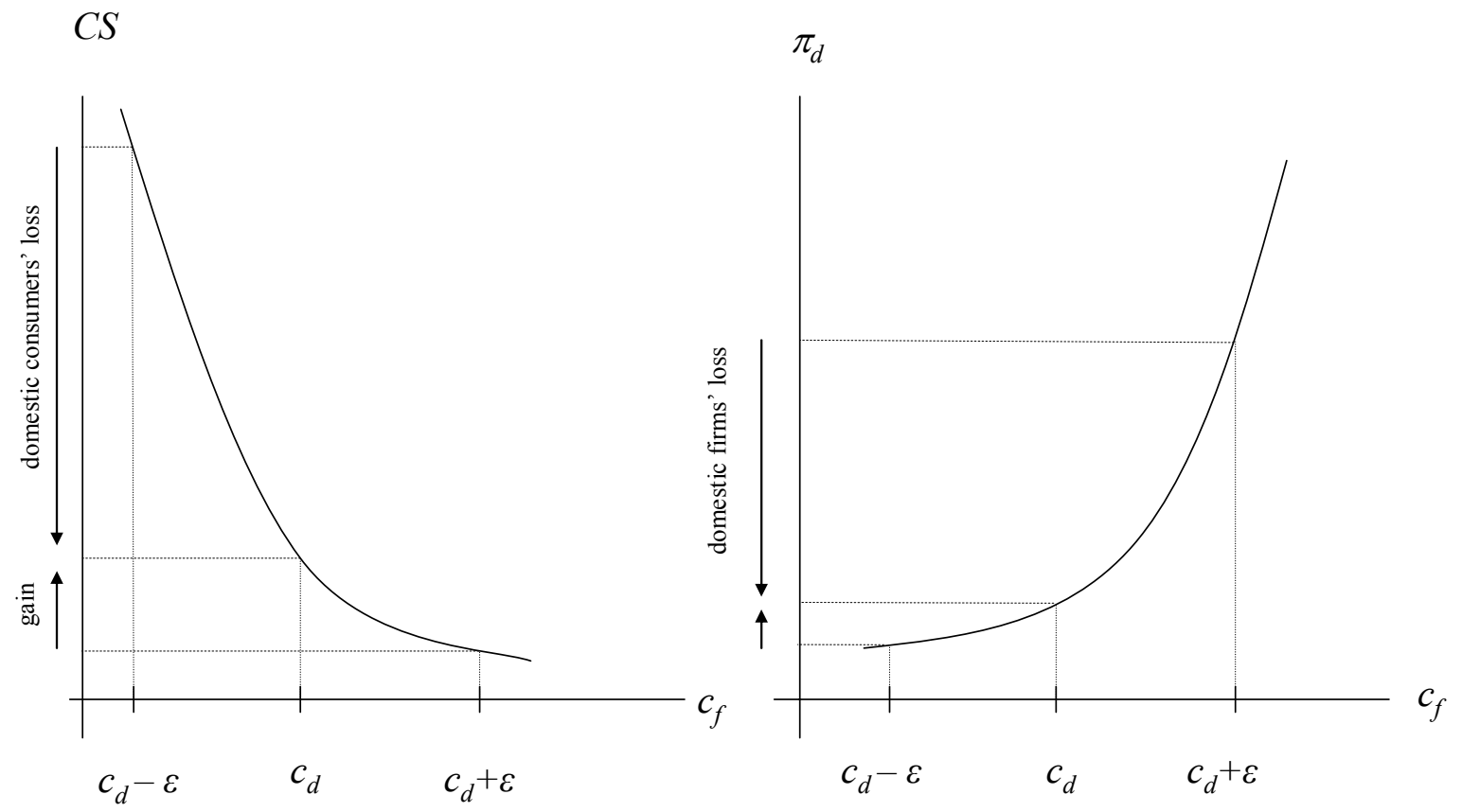


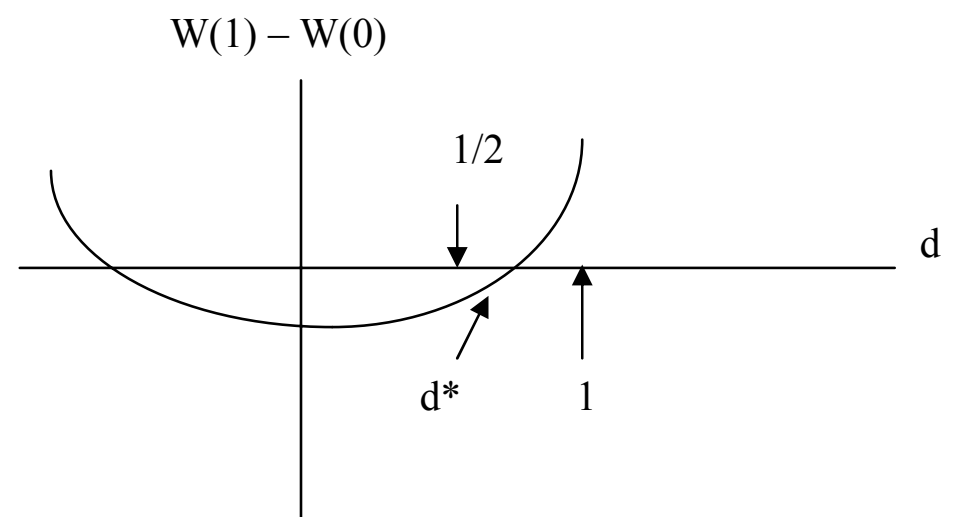

FIGURE 2 (cost increasing FDI)

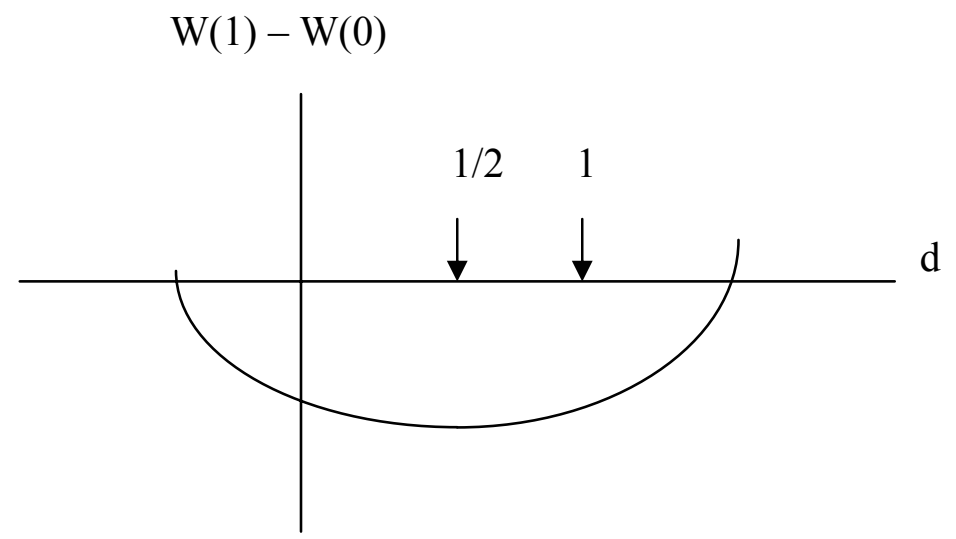

FIGURE 3 (cost-increasing FDI)

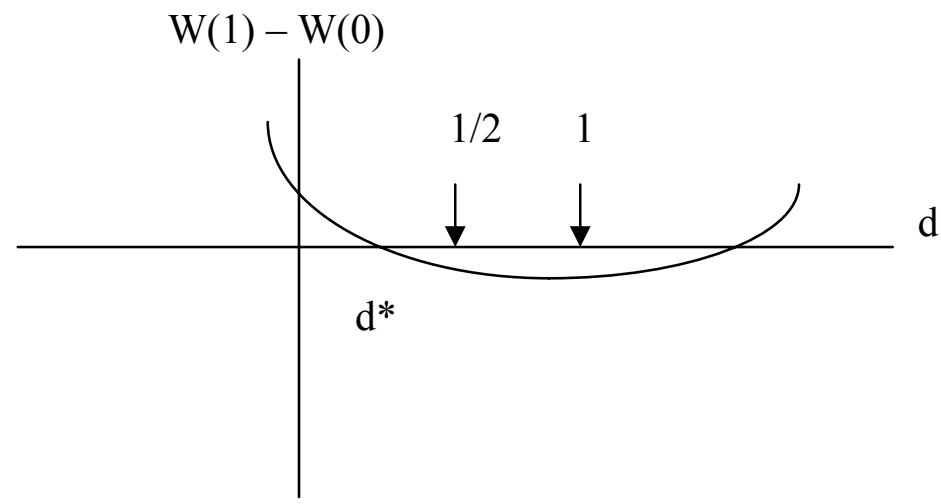

FIGURE 4 (cost-reducing FDI) 